\title{
Teaching Communication Strategies in an EFL Class of Tertiary Level
}

\author{
Muhammad Sukirlan \\ Teacher Training and Education Faculty, University of Lampung, Indonesia
}

\begin{abstract}
This article deals with the effects of teaching communication strategies (CSs) on the types of communication strategies used by the students and level of speech comprehensibility. This research is largely experimental involving 23 students. The research isntruments include vocabulary test to identify students' unknown objects, treatment, and observation. Descriptive qualitative analysis was used to analyze the linguistic features, and repeated measure t-test was used to analyze the level of speech comprehensibility. The results reveal that (1) in terms of frequency, there are increases in 4 types CSs, decreases in 7 types of CSs, and a consistancy in one type of CS, (2) there is a significant increase in the level of speech comprehensibility. Therefore, it can be concluded that teaching communication strategies prommote students' communication skills.
\end{abstract}

Index Terms - comunication strategy, comprehesibility, foreignizing, time-stalling

\section{INTRODUCTION}

In Indonesian context of English Language Teaching (ELT), the goal of teaching English is to develop the students' communicative competence, that is, having substantial ability to communicate in variety of communicative situations. However, there is an indication that students' oral production is unsatisfactory (see e.g. Cahyono \& Widiati, 2008; Setiyadi, 2009; and Rachmawaty \& Hermagustiana, 2010). Therefore, there seems to be in need to include the teaching of communication strategies in the classroom context.

For the sake of pedagogical reasons, this artcile views that communication strategy teaching deserves a place in the classroom on the basis of several reasons. First, communication strategy training may promote learners' awareness to use their linguistic resources to minimize communication problems. Second, strategic competence is a part of learner's communicative competence. Third, communication strategy training bridges the gap between classroom and real-life communication. Finally, communication strategy training contributes to the students' security, self-confidence, and motivation to communicate.

This article, therefore, examines the effects of teaching communication strategies on the realization of communication strategies both qualitatively (the features of each type of communication strategies used by the students, and quantitatively (frequency of the strategies used and level of speech comprehensibility).

\section{LITERATURE REVIEW}

Communication strategies are generally defined as the ways in which a speaker attempts to solve communication problems to reach particular communicative goals (e.g. Faerch \& Kasper, 1983; Dörnyei, 1995; Faucette, 2001; Tarone, 2005; Lam, 2006; Maleki, 2007; Aliakbari \& Allvar, 2009). When attempting to communicate a message to listeners, a speaker may have to struggle to find appropriate expressions and grammatical constructions to compensate for gaps between what he/she intends to express and the available linguistic resources.

The study of communication strategies (CSs) can be traced through the work of Selinker (1972) on interlanguage, which introduces the notion of communication strategies, on the basis of which Veradi (1973) and Tarone (1977) produce systematic analysis of communication strategies. Since then, there has been a growing increase in the number of studies dealing with communication strategies. However, different researchers see communication strategies from different points of view, which can be observed in terms of the perspective of CSs, the taxonomy of CSs, the variables affecting CSs, the use of CSs in L1 and L2, and the strategy training of CSs.

First, communication strategy is defined in two main theoretical perspectives - interactional and psycholinguistic. Interactionalist scholars (e.g. Veradi, 1993; Tarone, 1977) focus on interactional view - the joint negotiation of meaning between interactants. Communication strategies are seen as attempts to bridge the gap between the linguistic knowledge of the speaker and the linguistic knowledge of the interlocutor. Meanwhile, psycholinguistic researchers (e.g. Faerch and Kasper, 1983; Bialystok, 1990; Poulisse, 1990; and Kellerman, 1991) are interested in the cognitive process in relation to the use of CSs. They discuss communication strategies in psycholinguistic terms. Communication strategies are seen as psychological problem-solving framework and are treated as mental phenomena which underlay actual language behavior (Ellis, 1985). Therefore, communication strategies are used to solve their communication problems. 
Second, in terms of the taxonomy of communication strategies, it is also traced that there are two main classifications of communication strategies, i.e. product-based and process-based classifications. The former follows the traditional conceptualization of communication strategies (e.g. Tarone, 1977; Tarone and Yule, 1989; Faerch and Kasper, 1983, Littlewood, 1989; Bialystok, 1990; and Chen, 1990) that produces the taxonomy of communication strategies based on linguistic products. The latter produces the taxonomy of communication strategies based on psycholinguistic phenomena, the proponents of which include among others Poulisse and Schills (1989), Kellerman (1991), and Littlemore (2003). This approach follows the assumption that identifying cognitive process underlying the choice of a strategy is essential. Therefore, the two frameworks above produced different approach in producing the typology of communication strategies.

Third, previous studies on communication strategies revealed that the use of communication strategies is influenced by several factors, i.e. learner's target language proficiency and situation of use. In the case of the former, it appears that students' linguistic proficiency may, to some degree, influence his/her choice of communication strategies (e.g. Tarone, 1977; Bialystok, 1983b; Ting and Lau, 2008; Aliakbari, 2009). In the case of the latter, learner's communication strategies were affected by the situation of use. For example, Ellis (1985) suggests that learners may use fewer strategies in a classroom environment than in a natural one, particularly if the pedagogical focus is on correct L2 rules rather than in fluent communication. A previous study conducted by Piranian (1979) found that American university students learning Russian relied more on avoidance, whereas learners with natural exposure used paraphrase. The findings seem to suggest that different situations might, to a certain degree, affect the learner's choice of particular communication strategies (see e.g. Rababah, 2002, 2005).

Fourth, previous studies concerning the use of communication strategies in L1 and L2 indicate that there is no correlation between strategy use and L1 background. The use of communication strategies is evident in L1 and L2. In other words, there is no difference between the use of communication strategies in L1 and L2 communication strategy use (e.g. Tarone, 1977; Tarone and Yule, 1989; Kellerman, 1991; and Lukmana, 1996).

The fifth area of focus in the study of communication strategies, which will be the focus of the present study, is communication strategy teaching. It is evident that responses to the teaching have been varied. Many scholars of communication strategies (e.g. Kellerman, 1991; Bialystok, 1990; Poulisse, 1990) believe that cognitive process is unaffected by instruction; therefore, communication strategies are not teachable. However, other scholars who focus on the language expressions used in identifying the types of communication strategies (e.g. Faerch \& Kasper, 1983; Dörnyei, 1995; Galagher Bret, 2001; Rositer, 2003a; Nakatani, 2005; Lam, 2006; Ya-ni, 2007; Tiwaporn, 2009; and Maleki, 2007, 2010) advocate the necessity to teach the linguistic expressions for effective L2 communication. In other words, communication strategy training deseves a place in language classroom contexts.

\section{A. Typology of Communication Strategies}

There are two main approaches of classifying communication strategies i.e. product-based classification and "process-based classification. Product-based has resulted the typology based on surface structural differences in the utterances and claimed that under such differences there are possibilities to express thoughts. In the light of the interactional approach, for example, Tarone (1977) reveals that there are strategies that can be used to overcome linguistic knowledge differences between second language learner and native speaker. There are 5 main categories: avoidance, paraphrase, conscious transfer, appeal for assistance, and mime.

Faerch and Kasper view communication strategies as a model of speech production that consists of planning phase (where the plan is developed), and execution phase (where the plan is executed). If a learner faces the communication problems so that the plan cannot be executed, he/she takes either avoids the problems which leads to a change of the communicative goal and reduction strategies, or faces the problems and develops an alternative plan which leads to achievement strategies.

Process-based classification proposes alternative taxonomy of communication strategies which is based on the assumption that identifying cognitive processes that underlie the choice of the strategy is essential, as well as, taking into account the factors involved in such selection. Kellerman (1991) claims that some of the strategies demonstrate the same underlying cognitive processes and should therefore not be classified as different strategies even if they are not generalized over task, language, and learner. He further criticized on the definition of the strategies, that are sometimes too vague, and the choice of some criteria, e.g. 'the construction of a new word' as a definition of 'word coinage' excludes all the words created by the learner but that already exist in the language.

The typology of communication strategies based on underlying processes involved in the production of the strategies make them psychologically plausible. Bialystok (1990) has expressed the importance of strategies differing in a psychologically correct way. The theory proposed is based on the distinction between 'analysis' (an attempt to convey the structure of the intended concept by making explicit the relational defining feature - the speaker modifies the content of the message by using his knowledge about concept) and 'control' (the manipulation of form of expression through attention to different sources of information) which is firmly grounded in cognitive psychology. The Nijmegen Project, includes Kellerman and Poulisse, uses a binary system based on conceptual and linguistic strategies. Conceptual strategies are either analytic or holistic. However, there are also cases where analytic and holistic are combined. Linguistic strategies involves morphological creativity and strategy of transfer 
A number of researchers on communication strategies have made some typologies of communication strategies. Different researchers have made attempts to group communication strategies in meaningful categories.

\section{B. Communication Strategies Used in the Present Study}

The typology provided by the proponents of communication strategies are grouped according to certain criteria: (1) the learner's choice as to whether to reduce or to achieve the goal; (2) to consult different source of information L1 or L2; and (3) to use the conceptual or linguistic knowledge. Therefore, it can be inferred that different researchers have used different typologies for classifying communication strategies. Some researchers used the same label of typology and some others use different names but refer to the same concepts/of communication strategies. Rababah (2002) confirmed that the terminology used to describe strategic behavior varies great deal, but the corresponding part of most existing strategies show many similarities. For example, compensatory strategy of Faerch and Kasper (1983) are convergent with the major strategies proposed by Tarone (1977); approximation, coinage, literal translation, paraphrase, avoidance, and appeal for help. Therefore, Bialystok remarks:

The varieties of taxonomy proposed in the literature differ primarily in the terminology and overall categorizing principle rather than in the substance of the specific strategies. If we ignore, then, differences in the structure of the taxonomies by abolishing the various overall categories, then a core group of specific strategies that appear consistently across the taxonomies clearly emerges. Differences in the definitions and illustration for these core strategies across the various studies are trivial. (Bialystok: 1990: p. 61)

Based on the typology of communication strategies proposed by the researchers above, there are basically only two main categories of communication strategies: reduction strategies and achievement strategies. The former is adopted by the learner who attempts to do away with a problem. They involve the learners giving up part of his/her original communicative goal and achievement strategies. The latter is taken by the learner when he/she decides to keep the original communicative goal but compensate for insufficient means, or makes the effort to retrieve the required items. However, after analyzing the two main strategies, the present study categorizes communication strategies into 12 strategies namely approximation, circumlocution, exemplification, comparison, word coinage, borrowing/code switching, foreignizing, repetition, non-verbal, avoidance, time-stalling device, and appeal for assistance.

\section{METHOD}

This research is largely experimental involving 23 students who are taking Intermediate Speaking class. One-grouppretest-and-posttest design was used and it was conducted through 3 steps. First, the students were tested to label photos of daily objects. Then, the students were asked to describe unknown object in order to elicit communication strategies. Second, the students were taught to be aware and to be able to use the twelve targeted communication strategies. Third, the students were tested to label photos of daily objects, then, they were asked to describe unknown objects in order to elicit communication strategies after the treatment. The realization of communication strategies were analyzed in terms of linguistic features, the frequency of occurrence, and level of speech comprehensibility.

The teaching of communication strategies was largely presented in 3 stages, i.e. orientation, exposition and practice. In orientation, the students were introduced with the types of communication strategies. The students were also taught how to use communication strategies to solve communication problems. In exposition, the students were exposed with dialogue of listening materials and they were asked to listen to the dialogue. After listening, the students were asked to identify particular communication strategies the speakers used in the dialogue. The students were also exposed with linguistic resources required for the success of using communication strategies like vocabulary aspects (i.e. material, shape, color, size, texture, parts, clothing, taste, synonym, antonym) and grammar aspects (i.e. tenses, passive voice). In practice, every student was given photos of unknown objects to be described in front of the class. Meanwhile, the audiences were asked to evaluate his/her performace in terms of the level of speech comprehensibility by scoring whcih ranged from 1 to 10 .

\section{RESULTS AND DISCUSSIONS}

This section attempts to answer the first issue raised in the first research problem, i.e. the effects of teaching communication strategies on the the types of communication strategies used by the learners. The answers of the question are based on two perspectives, i.e. features and frequency of communication strategy used.

\section{A. Features of Communication Strategies}

Approximation serves as one of the communication strategies whereby the speaker uses a single target language vocabulary item or structure, which the speaker knows is not correct, but which shares enough semantic features in common with the desired item. Before teaching, approximation was characterized by 2 types of features, i.e. expectancy and hyponymy relation. After teaching, this strategy was characterized by 3 types of features, i.e. expectancy, hyponymy, and synonymy relations. In the case of expectancy relation, the student produces "This object is used in children's head to arrange their hair." The student approximates the word "hair band" with location it is normally place, i.e. "head" and and its function, i.e. "to arrange thier hair". While hyponymy relation is made by producing utterance like "It is the tool to dig the soil" when describing "shovel". The shovel is the type of tool. Example of synonymy 
relation is "It is a sweeper ...to clean the rubbish from the floor". The student approximates "plam-rib broom" with "sweeper

Circumlocution is saying in many words what may be said in few words. More specifically, circumlocution is defined as a change in preverbal message involving more than single chunk. Realizing that the speaker encounters communication problem with the interlocutor, he/she circumlocutes the words by describing the properties of the object or action instead of using appropriate target language item or structure. There are 7 features of circumlocution used by the students, i.e. material, locational. elaboration, color, shape, function, and size.

Material type of circumlocution was characterized by linguistic features such as it is made of/from/by...., it is from...., it is the mixture of..., you need cement, sand. Locational was characterized by linguistic features such as it is found in front of..., it is found in..., it is located in..., we put it in...., etc. Elaboration was characterized by linguistic features such as conditional relation (if + subject + verb, subject + verb), cause and effect relation (because + Subject + verb, subject + verb), and sequential relation (before/after + Subject + verb, subject + verb). Color was characterized by linguistic features such as it is yellow/green/white/red..., and the color is ..., it will be red/green ..., it has many colors like blue, yellow..., and the color can be ...etc. Shape was characterized by linguistic features such as the shape of this object is..., ... and the shape is like..., it is square/triangle...., it has many shapes like... Functional was characterized by linguistic features such as ...it is used to/for/by..., the function of this object is for..., you use this object for..., you can use it for... And lastly, size was characterized by linguistic features such as ...the size is ...., it is big/small/large..., the height is ...., and it measures about ...., it has many sizes such as...., the weight is

Exemplification is defined as illustrating the unknown object by giving an example. The speaker gives examples such as stories, people, occasions, and novels that reflected the meaning of the concept (Chen, 1990). The most common feature of exemplification is by using the phrases such as for examples, for instances, examples include, etc.

Comparison is the act of examining, judging to what extent person or things are similar or not similar. This strategy is characterized by feature, i.e. analogy, synonymy and negative comparison i.e. contrast and opposition, antonymy. Examples of comparison the students used for performing the communication tasks are This is the same as rectangulars, It will be cleaner than before, It makes the room more beautiful.

Word coinage means the speaker invents a new word to maintain the flow of communication. The speaker creates new word or phrase by applying L2 morphological rules to an L2 word hoping that he/she will be able to express the desired meaning (Faerch \& Kasper, 1984; Kellerman, 1991). Examples of features of word coinage the students used for performing the communication tasks are half-triangle for easel, main body for tree trunk, bodiless for shapeless

Code-switching is identified by the speaker's use of native language when speaking in an L2 (see e.g. Faerch \& Kasper, 1984; Littlewood, 1989; Bialystok, 1990). Code-switching strategies might be the commonest communication phenomena found in non-native language learners who have the same native language background. When the speaker encountered communication problem, he/she resorted to borrowing/code-switching certain word or phrases in L1. Tarone (1977) used the term as "language mix strategy", Littelwood (1989) used "switch to the native language". The speaker resorted to the native language because he/she realized that the listeners had the same native language with the speaker. Cook (1996) confirms that the profile of the proficient L2 user includes the code-switching mode of language. It is not something that is peculiar or unusual. If the bilingual knows that the listener shares the same languages, codeswitching is likely to take place for all the reasons given above. Paramashivam (2009) also confirms that the learners' first language functions as a strategy for communication but also how it can enhance second language learning by way of helping learners expand their second language repertoire and increase their automatization of second language item.

Based on the results of analysis, the students' frequent use of L1 were categorized into word such as 'zikir' [praying], 'memutar' [turn around], 'lengan' [sleeve], and expressions such as 'Aduh!'[Ouch!], 'Apa ya?'[What is it?]', 'Apa sih?' [What is that], 'Apa?' [What?]'. However, in terms of using proper names like Ramayana [Hindu epic], Rumah Gadang [Padangese traditional big house], and Siger, [Lampungese wedding crown] the speaker probably had no way of using target language because the terminologies were only found in native language culture. For examples, siger is found in Lampung province referring to Lampungese traditional crown worn on the head of a groom, rumah gadang is found only in West Sumatra referring to West Sumatra's traditional big house occupied by more than one family, and Ramayana is found in Indonesia that refers to great Hindu epic from which many themes of Indonesian literature and public life are drawn.

However, after teaching, the students' use of code-switching was still found, although the prevalence was not as many as there were before teaching. However, the students' use of L1 occurred only in the level of word but not in expression such as "Ramayana", "rumah gadang", "siger", "muncrat" [spray]. The decrease in the number of codeswitching after eaching seems to indicate that the teaching of communication strategy gave positive effect on the students' realization of communication strategies because they relied more on TL-based strategies such as circumlocution, approximation, comparison to deliver messages to the listeners. In other words, after the teaching the students were more confident to use TL-strategies rather than L1-based strategies.

Foreignizing is defined as the speaker's use of a non-L2 form but adapt it to make it appear like a L2 form (see e.g. Faerch \& Kasper, 1984; Bialystok, 1990; Faucette, 2001). Before teaching, it was identified that there was only one linguistic feature of foreignizing. The newly invented word "to bor" was used by the student to refer "to drill" the soil or "to make a hole". The use of "to bor" may be influenced by the word in Indonesia "mengebor tanah" which means 
"to make a hole of the soil". Foreignizing was probably common phenomena found in the second language learners who performed communication tasks as they had inadequate linguistic resources. However, no linguistic feature of foreignizing was found after the students had learned how to use commuication strategies. Therefore, iit can be inferred that teaching communication strategy gave positive effect on the students' realization of communication strategies in the way that it can reduce the students' misconception of the target language rules.

Repetition is defined as the speaker's passing on the old information by repeating what he/she had said in the previous turns. In the present study, repetition is used because the speaker takes time of what will be said next. Repetition occurs in word level and expression level. The speaker's use of repetition was classified into word level and expression level. Examples of the words level were " to open", "the bottle", "rice", to dig", "to open the screw", "our mother", "circle" "a place", "you usually...", "in paper", "small thing", "when we...", "this place", "to lie", "dining room", "to describe", "dig the soil", "in the pan", "it's name", whereas the examples of expression level such as in "we use it", "it is used", "it is useful to take the water", "we always used for...", "it is used to..".

Based on the data found after the teaching, the use of repetition was still in found in two levels word level and expression level. Examples of word level were "additional lock", "rib", whereas expression level were "it is made of....", "it is used to...". The students made less frequent repetition after training than did before training. In other words, the teaching of communication strategy gave positive effect in the way that it can reduce the students' use of repetition. The finding is in line with research conducted by Dörnyei (1995) who found that communication strategy training has direct impact on the students' speech rate.

Non-verbal serves as one of the communication strategy used by learners. The use of non-linguistic means in place of a lexical item (Littlewood, 1989; Bialystok, 1990; Faucette, 2001). This strategy is characterized by featuresn such as mime, gestures, facial expression, etc. Non-verbal as one of the strategies used was found not only from the linguistic data in transcription but also from observation.

The students did many things possible to make his/her speech comprehensible by using non-linguistic strategies. Other features of non-verbal are (1) showing where the hair band was worn, (2) showing how to use abacus, (3) showing the shape of pliers by drawing an ' $\mathrm{X}$ ' letter, (4) showing the action of digging to describe shovel, (5) showing the irregular shape of can opener, (6) showing the act of taking the cake using cake tweezers, (7) showing the act of bunching the hair to describe hair pin, (8) showing the shape of right three angle to describe easel, and (9) showing the irregular shape of barbed wire by drawing. The prevalence of non-verbal strategies before and after training is equal. The finding seems to indicate that non-verbal strategies are still well liked by the students because these strategies are helpful to support delivering messages to the listeners. Dörnyei (1995) supports that some people can communicate effecttively in an L2 with only 100 words by using their hands, they imitate the sound or movement of things.

Avoidance is identified as the speaker simply does not talk about the concept for which the target language item or structure is not known (Tarone, 1977; Bialystok, 1990; Faucette, 2001). The transcript of the interview might support the reasons for the students to employ avoidance. By comparing the data before and after teaching, it was found that (1) the linguistic feature of avoidance before and after teaching is similar, (2) the main reason for the students to use avoidance is their lack of target language resources.

Time-stalling device is used when the speaker realizes that he/she encounters communication problem with interlocutor. Time-stalling device is identified when the speaker begins to talk about a concept but cannot continue and stop in the mid-utterance (Faerch \& Kasper, 1984; Faucette, 2001). This strategy is characterized by a silence or filler in the mid utterance. The finding seemed to imply that the students were more fluent in arranging the sentences for describing the objects after being trained in the posttest than in the pretest. The transcript of the interview might support the reasons for the students to employ time-stalling device. The findings seem to indicate that students' speech rate increases after learning how to used cmmunication strategies. The finding confirms Dörnyei's (1995) result of research that communication strategy training has direct impact on the students' speech rate.

Appeal for Assistance is used in order to maintain the flow of communication, the speaker appeals for assistance (see e.g. Tarone, 1977; Faerch \& Kasper, 1984; Bialystok, 1990). This strategy is characterized by the use of expression signaling direct appeal such as "What is this?", "Do you know how to say this in English?" etc. A question was used as a clue of appeal for assistance to the interlocutors. The students used appeal for assistance strategies not only in the target language like "What is it?", "What?", "Can you imagine that?" but also in the native language like "Apa sih? [What is it?], "Apa ya?" [What is it?]. 
TABLE 3:

THE FEATURES OF COMMUNICATION STRATEGIES THE STUDENTS PRODUCED

\begin{tabular}{|c|c|c|}
\hline No. & Types of Communication Strategy & Features \\
\hline 1. & Approximation & hyponimy relation, synonimy relation, and expectancy relation \\
\hline 2. & Circumlocution & $\begin{array}{l}\text { material, locational, elaboration (conditional relation, cause and effect relation, } \\
\text { sequential relation) color, shape, functional, size }\end{array}$ \\
\hline 4. & Comparison & analogy, synonymy and negative comparison i.e. contrast and opposition, antonimy \\
\hline 5. & Word Coinage & $\begin{array}{l}\text { Word creation like box of drug for medicine box, to on the lamp for socket, half- } \\
\text { triangle for easel, main body for tree trunk, bodiless for shapeless }\end{array}$ \\
\hline 6. & Code-switching & $\begin{array}{l}\text { Word level like zikir (praying), memutar (turn around), lengan (sleeve), expression } \\
\text { level like Apa sih (what is it?), Aduh, apa ya? (Ouch, what is it?), and proper noun } \\
\text { like rumah gadang (Padangese traditional big house), Ramayana (Hindu Epic) }\end{array}$ \\
\hline 7. & Foreignizing & Verbial phrase like to bor for to drill \\
\hline 8. & Repetition & $\begin{array}{l}\text { Word level like to open, the bottle, to dig, etc., and expression level like it is made } \\
\text { of..., it is used to..., it is used to take water... }\end{array}$ \\
\hline 9. & Non-verbal & mime, gestures, facial expression \\
\hline 10. & Avoidance & Avoid the topic and altering to other topic \\
\hline 11. & Time-stalling Device & a silence, filler \\
\hline 12. & Appeal for Assistance & $\begin{array}{l}\text { the use of expression signaling direct appeal, i.e. asking question to the audience "Do } \\
\text { you know what it is? }\end{array}$ \\
\hline
\end{tabular}

\section{B. Frequency of Communication Strategies}

This subsection presents the data concerning the communiction strategies used by the students. The report reveals the commonest type of communication strategy and the less common type of communication strategy used by the stsudents.

Before teaching, it can be reported that approximation occurred 5 times, circumlocution 97 times, exemplification 4 times, comparison 8 times, word coinage 3 times, code-switching 16 times, foreignizing once, repetition 32 times, nonverbal 19 times, avoidance 41 times, time-stalling device18 times, and appeal for assistance 29 times.

After teaching, it was found that approximation occurred 13 times, circumlocution 290 times, exemplification 5 times, comparison 7 times, word coinage 3 times, code-switching 4 times, no foreignizing occurred, repetition 9 times, nonverbal 20 times, avoidance 15 times, time-stalling device 12 times, and appeal for assistance 17 times. In other words, there are increases in 4 types of communication strategies such as approximation, circumlocution, exemplification, and non-verbal. The only communication strategy constantly occurring was word coinages, and there are decreases in 7 types of communication strategies such as comparison, code-switching, foreignizing, repetition, avoidance, timestalling device, and appeal for assistance.

The results can probably be explained by considering the following aspects. Firstly, based on the result it seems to indicate that after participating in the oral communication strategy teaching, learners made a significant increase in various types of communication strategies such as approximation, circumlocution, exemplification, and non-verbal. The data seem to indicate that strategy training gives positive effects in the way that it makes the students capitalize the target linguistic resources (TL-based strategies) to deliver the message to the listeners in the class.

Secondly, the results of the analysis show that there was a decrease in the frequency of the communication strategies such as code-switching, repetition, avoidance, time-stalling device, and appeal for assistance. The facts seem to indicate that the strategies training gives positive effects it the way that the teaching can increase the students' fluency of expressing their ideas using the target linguistic resources. In other words, after the students had participated in communication strategy teaching, they were more confident to perform their communication tasks in front of the class. The students were more skillful to use the communication strategies to deliver the opinion to the listeners in the lass. As has been confirmed, fluency is the one of the aspects influencing the speaking skills (Harris, 1974; Heaton, 1988). The table 4 below shows the frequency of each type of communication strategy used by the students.

TABLE 4:

FREQUENCY OF COMMUNICATION STRATEGIES USED BY THE STUDENTS

\begin{tabular}{|l|l|l|l|l|}
\hline No. & $\begin{array}{l}\text { Types of Communication } \\
\text { Strategy }\end{array}$ & $\begin{array}{l}\text { Frequency of Occurrence } \\
\text { before Teaching }\end{array}$ & $\begin{array}{l}\text { Frequency of Occurrence } \\
\text { ffter Teaching }\end{array}$ & Mark \\
\hline 1. & Approximation & 5 & 13 & increase \\
\hline 2. & Circumlocution & 97 & 290 & increase \\
\hline 3. & Exemplification & 4 & 5 & increase \\
\hline 4. & Comparison & 8 & 7 & decrease \\
\hline 5. & word coinage & 3 & 3 & constant \\
\hline 6. & Cod-switching & 16 & 4 & decrease \\
\hline 7. & Foreignizing & 1 & 0 & decrease \\
\hline 8. & Repetition & 32 & 9 & decrease \\
\hline 9. & Non-verbal & 19 & 20 & increase \\
\hline 10. & Avoidance & 41 & 15 & decrease \\
\hline 11. & Time-stalling device & 18.4 & 12.6 & decrease \\
\hline 12. & appeal for assistance & 29 & 17 & decrease \\
\hline
\end{tabular}


Based on the table above, it can be inferred that the most frequent communication strategies used by the students was circumlocution while the least communication strategies used was word coinage. The finding seems to be in line with the study conducted by Bialystok (1990). Bialystok compared some of the communication strategies in terms of the effectiveness and found that the listeners understand word coinage much better than approximation, circumlocution, or language switch, though in terms of sheer frequency, word coinage was very rare, the commonest strategy being circumlocution. Circumlocution is especially useful to solve gaps of communication in order to keep the flow of conversation. In addition, circumlocution functions as facilitative role of compensatory strategies as a tool to cope with problematic vocabulary (Campillo, 2008).

\section{Level of Comprehensibility}

Before teaching, the data showed that the average score of the level of comprehensibility before teaching was 5.1 and there were 5 students (22\%) whose score reached above 6.0, and 6 students (26\%) reached above 5.0, and 12 students (52\%) reached above 4.0. After teaching, the results indicated that the average score of the level of comprehensibility was 69.75 and there was only 1 student (4.3\%) whose score reached 82, and 12 students (52\%) reached above 70, and 10 students $(43 \%)$ whose score reached 60 . From the data, it could be inferred that there was only one student who got the highest score of 82 and 10 students who got the score between 60 and 70.

By comparing the data before and after teaching, the results reveal that, interestingly, all students made significant progress in the level of speech comprehensibility. The students' average score of the level of speech comprehensibility before teaching was 5.1 while after teaching was 6.9. The increase seems to suggest that the students made the tendency of improvement by 1.8 point of the mean.

The increase of the level of speech comprehensibility seemed to indicate that the students were more successful in finding ways of linguistic adjustment such as being more aware of using more vocabularies that were still in the world of the listener and employing less complex syntax (e.g. using simple present tense, simple past tense, present continuous tense) for describing the objects. This is in line with Hatch (1979) who pointed out that there were three characteristics of the linguistic aspects that appeared to promote comprehension: (a) slower rate and clearer articulation, which helps acquirers to identify word boundaries more easily, and allows more processing time, (b) more use of high frequency vocabulary, less slang, fewer idioms, (c) syntactic simplification, shorter sentences.

In addition, since the students focused on how to make the speech comprehensible, they seemed to focus on how to make the message delivered and understandable. They did whatever they could do by using both linguistic and paralinguistic aspects to make the message across the listener. On the part of the listeners, they make use of, one of them, semantic link between one word with other words to get the idea of what was delivered by the speaker. Krashen (1995) argues that optimal input focuses of the acquirer on the message and not on the form.

The quantitative analysis relating to the hypothesis indicated that the students' level of speech comprehensibility increased after the students had participated in the communication strategy training. The finding can probably be explained that the strategy training the students participated enables them to practice producing the language output more comprehensibly as they get feedback not only from other students but also from the teacher. Hedge (2002) supports that learner needs practice in producing comprehensible output using all the language resources they have already acquired. Getting feedback from the teacher and from other students in the class enables learners to test hypotheses and refine their developing knowledge of the language system. It has also been claimed that being pushed to produce output obliges learners to cope with their lack of language knowledge by struggling to make themselves understood, by speaking slowly for example, by repeating or clarifying their ideas through rephrasing.

The t-test results presented in table 5 showed that there was a difference in the students' level of speech comprehensibility before and after being taught. The next question would be "Is the difference of 18.47 between the mean of pretest and that of the posttest a significant progress?" The result of Matched t-test as presented in the following table provided the answer.

Table 5 showed that the value of t-ratio was 13.975 while the critical value for t-table was 2.074 . This indicates that the value of 13.975 exceeds 2.074. Therefore, the researcher is confident to conclude that the treatment did have effect on the students' level of speech comprehensibility. Students' score differed significantly from pretest to posttest. Therefore, we can eventually accept the hypothesis that there was a significant improvement of the students' level of speech comprehensibility following the treatment through teaching of communication strategies.

TABLE 5:

MATCHED T-TEST GAINS OF THE LEVEL OF SPEECH COMPREHENSIBILITY

\begin{tabular}{|l|l|l|l|l|l|l|}
\hline Group & $\mathrm{N}$ & Mean & t-ratio & t-table & df & P \\
\hline Pretest & 23 & 5.126 & 13.975 & 2.074 & 22 & 0.05 \\
\hline Posttest & 23 & 6.973 & & & & \\
\hline
\end{tabular}

\section{The Overall Effects of Teaching Communication Strategy}

Based on the qualitative and quantitative analysis, the teaching of communication strategy conducted in the present study gives notable effects on varieties of aspects. The strategy training affects on the increase number of linguistic 
features in several type of communication strategies such as approximation, circumlocution, exemplification, and nonverbal.

By contrast, the qualitative analysis of the present study also indicates that there were decreases in the number of code switching, foreignizing, repetition, avoidance, time-stalling device, and appeal for assistance. The decrease in the use of such strategies might indicate positive effects in several points: (1) the decrease in the use of code switching might indicate that students rely more on the target language than native language resources for expressing ideas, (2) the students used less foreignizing might indicate that they were more able to use target language vocabulary and structure, (3) the students used less repetition seems to indicate that the students were more fluent to speak in target language, (4) less use of avoidance might indicate that the students were more able to get the meaning across to other students as they had sufficient target linguistic resource, (5) less use of time-stalling device might indicate that the students' speech rate increase after the training, (6) less use of appeal for assistance might indicate that the students were become more autonomous (see e.g. Wei, 2008) in the way that the students are able to use communication strageies to overcome communication problems with minimum assistance from others.

The statistical analysis indicates that strategy training seems to give significant effect on the number of circumlocutions used by the students and the level of speech comprehensibility. The students' total use of circumlocution was 97 before the teaching and increased to 290 after the teaching. After analyzing, it was found that $t-$ ratio was 10.03192 while t-table was 2.074 . Since t-ratio is higher than t-table, it can be conluded that strategy training gave significant effect on the number of circumlocution. It seems to indicate that after being trained, the students were able to find more alternative ways to deliver message to other students.

In terms of the students' speech comprehensibility, it was found that the level of speech comprehensibility before the teaching was 5.126 and after the teaching was 6.673. The statistical calculation indicates that t-ratio was 13.975 while $t-$ table was 2.074. Since t-observe was higher than t-table, it indicates that strategy training gave significant effect on the students' level of speech comprehensibility. In other words, after the training the students' speech was more comprehensible. The listeners were more easily to understand the speaker's speech.

Finally, the finding of the present study seems to confirm that language is best learned and taught through interaction; hence, teaching communication strategies is the recommended fulcrum by which strategic competence can be developed (see e.g. Faerch and Kasper, 1984; Tarone and Yule, 1989, and Maleki, 2007).

\section{CONCLUSION}

Based on the findings, it can be conluded that students encountered communication problems as the results of their target linguistic inadequacy. In order to overcome the problems, the students resort to several types of communication strategies. The findings of the present study show that students' use of communication strategies is not a sign of communication failure, conversely, communication strategies surfaced as they realize that they have problems of expressing their intended meaning and they need to solve the problems. The more communication strategies the students have, the more opportunities they have to solve communication problems. Therefore, explicit instruction on the use of communmiction strategies is necessary to help the students communicate their message when target linguistic resources is inadequate.

\section{REFERENCES}

[1] Aliakbari, M. and Allvar, N.K. (2009). Communication strategies in the Written Medium: The Effect of Language Proficiency. Linguistik Online 40. 4/09.

[2] Bialystok, E. (1983). Some factors in the selection and implementation of communication strategies. In C. Faerch and G. Kasper (eds.), Strategies in Interlanguage Communication. London: Longman.

[3] Bialystok, E. (1990). Communication Strategies: A Psychological Analysis of Second-Language Use. Oxford. Basil Blackwell.

[4] Cahyono, B.Yudi \& Widiati, U. (2008). The Teaching of EFL Vocabulary in the Indonesian Context: The State of the Art. TEFLIN Journal Volume 19 Number 1 February 2008, 1-17.

[5] Campillo, P. S. (2006). The Use of Circumlocution in the Foreign Language Context. Porta Linguarum No. 5. enero 2006, 7-15.

[6] Cook, V. (1996). Second Language Learning and Language Teaching. Bristol. Arnold.

[7] Chen, S.Q. (1990). A Study of Communication Strategies in Interlanguage Production by Chinese EFL Learners. Language Learning Journal 40:2, June, pp. 155-187.

[8] Dörnyei, Z. (1995). On the teachability of communication strategies. TESOL Quarterly, 29, 55-95.

[9] Ellis, R. (1985). Understanding Second Language Acquisition. Oxford. OUP.

[10] Faerch, C. and G. Kasper, (1984). 'Two ways of defining communication strategies.' Language Learning 34/1, 45-63.

[11] Faerch, C. and G. Kasper, (1983). 'Plans and strategies in foreign language communication. In C. Faerch and G. Kasper (eds.). Strategies in Language Communication (eds.). London. Longman.

[12] Faucette, P. (2001). Pedagogical perspective on communication strategies: Benefits of training and analysis of English language teaching materials. Second Language Studies, 19(2), Spring 2001, pp.1-40.

[13] Gallagher, B. A. (2001). Teaching communication strategies to beginners. Language Learning Journal, $24,53-61$.

[14] Heaton, J.B., (1988). Writing English Language Test: A Practical Guide for Teachers of English as a Second or Foreign Language. England. Longman Group UK Ltd.

[15] Harris, D. P. (1974). Testing English as a Second Language. India. McGraw-Hill Book Company, New York. 
[16] Hatch, E. (1979). Apply with caution. Studies in Second Language. Acquisition 2: 123-143.

[17] Hedge, T. (2002). Teaching and Learning in the Language Classroom. Oxford. Oxford University Press.

[18] Kellerman, E. (1991). Compensatory strategies in second language research: a critique, a revision, and some (non-) implication for the classroom. In R. Phillipson, E. Kellerman, L.Selinker, M. Sharwood Smith and M. Swain. (eds.), Foreign and Second Language Pedagogy Research: A Commemorative Volume for Claus Faerch. Clevedon, UK: Multilingual Matters.

[19] Krashen, S. D. (1995). Principles and Practice in Second Language Acquisition. Mayland Avenue, Hemel Hempstead. Phoenix ELT.

[20] Lukmana, I. (1996). Communication Strategies in L1 and L2. Unpublished M.A. Thesis. Victoria: Faculty of Arts of Deakin University.

[21] Littlemore, J (2003). The Communicative effectiveness of different types of communication strategies. System. 31 (3). University of Birmingham institutional Research Archieve.

[22] Littlewood, W. (1989). Foreign and Second language Learning; Language Acquisition research and its implication for the classroom. Cambridge. CUP.

[23] Lam, W.Y.K. (2006). Gauging the effect of ESL oral communication strategy teaching: A multi-method approach. Electronic Journal of Foreign Language. Vol. 3, No. 2 pp. 142-157.

[24] Maleki, A. (2007). Teachability of Communication Strategies: An Iranian experience. System. Vol 35. Issue 4. December 2007 pp 583-594.

[25] Maleki, A. (2010). Techniques to Teach Communication Strategies. Journal of Language Teaching and Research, Vol. 1, No. 5, pp. 640-646, September 2010.

[26] Nakatani, Y. (2005). The Effect of Awareness-Raising Training on Oral Communication Strategy Use. The Modern Language Journal, 89,i,(2005) 0026-7902/05/76-91.

[27] Paramasivam, S. (2009). Language Transfer as a Communication Strategy and Language learnng Strategy in Malaysian ESL Classroom: Asian EFL Journal. Vol. 11. Issue 1 Article 10.

[28] Piranian, D. (1979) "Communication Strategies for Foreign Learners; A Pilot Study" Unpublished Manuscript, Department of Slavic Linguistics, University of Washington.

[29] Poulise, N. (1990). The use of Compensatory Strategies by Dutch Learners of English. Dordrecht: Foris.

[30] Poulisse, N. and Schills, E. (1989). The Influence of Task and Proficiency Related Factors on the Use of Compensatory Strategies: A Quantitative Analysis. Language Learning 39, 15-48.

[31] Rachmawaty, N. \& Hermagustiana, I. (2010). Does Retelling Technique Improve Speaking Fluency? TEFLIN Journal Volume 21 Number 1 February 2010, 1-8.

[32] Rossiter, M.J. (2003a). 'It's like chicken but bigger': Effect of communication strategy in the ESL clas sroom. Canadian Modern Language Review, 60, 105-121.

[33] Rababah, G. (2005). Communication Problems Facing Arab Learners of English. Journal of Language and Learning Vol. 3 No. 1 ISSN 1740-4983, 180-197.

[34] Rababah, G. (2002). Second Language Communication Strategies: Definitions, Taxonomies, Data Elicitation Methodology and Teachability Issues. A review Article. EDRS Price MF01/PC02 Plus Postage.

[35] Selinker, L. (1972). 'Interlanguage.' International Review of Applied Linguistics X: 209-230.

[36] Setiyadi, Ag. B. (2009). Language Learning Strategy Questionnaire (LLSQ): Step Towards The Success in Teaching English. Presented at the Professorship Inauguration, Novermber 24, 2009. Bandar Lampung. Lampung Univerisity Press.

[37] Tarone, E. (1977). "Conscious communication strategies in interlanguage: a progress report" in H. Brown, C. Yorio, and R. Crymes (eds). On TESOL'77. Washington D.C.: TESOL.

[38] Tarone, E. (2005). Speaking in a Second Language. In E. Hinkel (ed.) Handbook of Research in Second Language Teaching and Learning, NJ: Lawrence Erlbaum.

[39] Tarone, E and Yule. (1989). Focus on Language Learner. Oxford. Oxford University Press.

[40] Ting, S.H \& Lau L.Y. (2008). Lexical and Discourse-based Communication Strategies of Malaysian ESL Learners. Malaysian Journal of ELT Research. Vol. 4 pp. 81-31.

[41] Tiwaporn, K. (2009). The Effects of Teaching Communication Strategies on Thai Learners of English. Doctoral Thesis. School of Education. University of Southampton.

[42] Veradi, T. (1973). 'Strategies of Target Language Learner Communication: Message Adjustment.' Paper presented at the Sixth Conference of the Romaniance-English Linguistic Project in Timisoara.

[43] Wei, Ch. (2008). Developing Laerners' Autonomy through Metacognitive Awareness Training in ELT. CELEA Journal (Bimonthly). August 2008 Volume 31, No. 4, 110-120.

[44] Ya-ni, Z. (2007). Communication Strategies and Foreign Language Learning. US-Chinese Foreign Language. Volume 5, No. 4 (Serial No. 43). April 2007, 43-48.

Muhammad Sukirlan has currently been teaching in English Education Study Program, Department of Language and Arts Education, Teacher Training and Education Faculty, University of Lampung, Indonesia since 1990. He earned Bachelor of English Education from Teacher Training and Education Faculty of University of Lampung in 1989. In 1992, he went to Singapore to obtain a certificate in Practice, Implementation and Techniques of TESOL. He earned Master's Degree in TESOL from University of Newcastle upon Tyne, UK in 1997. In 2001, he went to School of International Training (SIT) Vermont, USA to obtain certificate on Training of Trainer for TOEFL and Multimedia in English Education. In 2011, he finished his Doctorate Degree in English Education from Indonesia University of Education (UPI-Bandung). His major interests are in Second Language Acquisition and English Education. 